\title{
Reinvestigation of Protelytron permianum (Insecta; Early Permian; USA) as an example for applying reflectance transformation imaging to insect imprint fossils
}

\author{
Olivier Béthoux ${ }^{1}$, Artémis Llamosi ${ }^{2,3}$, and Séverine Toussaint ${ }^{1,4}$ \\ ${ }^{1}$ Sorbonne Universités, UPMC (Paris 6), MNHN, CNRS, UMR 7207, Centre de recherche sur la Paléobiodiversité et les \\ Paléoenvironnements (CR2P), Paris, France \\ ${ }^{2}$ Sorbonne Paris Cité, Université Paris Diderot (Paris 7), CNRS, UMR 7057, Laboratoire Matière et Systèmes Complexes \\ (MSC), 10 rue Alice Domon et Leonie Duquet, Paris, 75013, France \\ ${ }^{3}$ INRIA Saclay, 1 rue Honoré d'Estienne d'Orves, Palaiseau, 91120, France \\ ${ }^{4}$ Sorbonne Paris Cité, Université Paris Diderot (Paris 7), UFR Sciences du Vivant, 5 rue Thomas Mann, Paris, 75013, France
}

Correspondence to: Olivier Béthoux (obethoux@mnhn.fr)

Received: 1 June 2016 - Revised: 5 August 2016 - Accepted: 15 August 2016 - Published: 2 September 2016

\begin{abstract}
We reinvestigated the holotype of Protelytron permianum, one of the earliest putative stem-dermapteran (i.e. stem-earwig). We recurred to reflectance transformation imaging (RTI) to deliver exhaustive and interactive photographic data. We were able to ascertain the occurrence of broadenings located along veins of the hind wing vannus and forming an arc, as well as a series of radiating folds, alternatively concave and convex. Such an organization is diagnostic of Dermaptera, in which it is indicative of hind wing folding mechanisms, particularly elaborated in these insects. We provide a foldable, paper model of the hind wing. Based on the case presented herein we anticipate that RTI process will be a major upheaval in the documentation of fossil insects preserved as imprints.
\end{abstract}

\section{Introduction}

Fossil insects preserved as imprints on a lamina (as opposed to specimens preserving complete 3-D structure, such as nodule- and amber-embedded ones) are sub-plane items whose subtle differences in relief can have critical implications regarding their systematic placement. This is especially true for wing venation. Producing a drawing prepared using various light orientations, with the aid of a drawing tube, is generally regarded as the best way to document such material. Concurrently, compelling photographic evidence can be laborious to obtain, as suitable light orientations are often unique and therefore difficult to produce. This situation leaves room for incomplete and/or unsupported interpretations (an issue also impacting the fossil record of Crustacea; Haug and Haug, 2014). A re-examination of specimens often necessitates loans or visits to the corresponding collections.

Archaeologists focusing on carved, inscribed, or even painted artefacts have traditionally faced similar difficulties. Photographic and computing techniques referred to as reflectance transformation imaging (RTI) have been developed in this field to solve these issues (Earl et al., 2010, and references therein). In short, these approaches compute, from a set of photographs, a single "interactive specimen" whose illumination can be modified at will. The data can be enhanced in various ways. This approach has already been applied to various types of fossil material (Hammer et al., 2002). Herein we report on our testing in documenting fossil insect imprints.

We selected the holotype of Protelytron permianum Tillyard, 1931 from the Artinskian Elmo locality (Early Permian; KS, USA) for its particular importance as putative age calibration point. According to Tillyard (1931) the species is among the earliest stem-dermapteran, (i.e. a fossil species more closely related to extant earwigs than to any other extant insect but which does not belong to crown-Dermaptera) together with other species from the same locality or of sub-identical age, forming the "Protelytroptera". Among these, $P$. permianum could be the closest relative of crown- 
Dermaptera, owing to the occurrence of vein broadenings located along an arc indicative of the occurrence of a ring fold, diagnostic of Dermaptera (Haas and Kukalová-Peck, 2001; Tillyard, 1931). However, the available data date back from the original description (Tillyard, 1931), complemented in Carpenter (1933), and are essentially composed of composite drawings. There is no published demonstrative photograph of the vein broadenings.

Moreover, the actual phylogenetic affinities of the "Protelytroptera" have been debated. While many (Haas, 2003; Haas and Kukalová-Peck, 2001; Hennig, 1981; Shcherbakov, 2002) have followed Tillyard (1931), considering this group a paraphyletic assemblage of stem-dermapterans, others have adopted a more cautious stance (Grimaldi and Engel, 2005; Laurentiaux, 1953; Rohdendorf, 1962 - English translation in 1991) or ignored this record ( $\mathrm{Nel}$ et al., 1994; Zhao et al., 2010). We noted that several authors who reproduced Carpenter's (1933) reconstruction omitted the critical vein broadenings (Hennig, 1981; Laurentiaux, 1953; Rohdendorf, 1962, 1991). We also noted that Carpenter (1933) advocated a lack of knowledge on the "method of folding of the hind wing" (p. 484), impeding, to his opinion, a definitive demonstration of the dermapteran affinities of the "Protelytroptera". Therefore, the selected specimen is particularly well suited for an approach delivering exhaustive photographic data.

\section{Material and methods}

The specimen which is the focus of the paper is housed at the Yale Peabody Museum (YPM IP 001019a,b; Figs. 1, 2). The block containing the specimen was prepared to avoid unwanted shading under lighting at low angle of incidence. A draft drawing was produced with the aid of a microscope equipped with a camera lucida (Zeiss SteREO Discovery V8 stereomicroscope equipped with a pair of W-PL $10 \times / 23$ eye pieces, a Plan Apo S 1.0× FWD objective; all Zeiss, Jena, Germany). Both sides of the specimen were used. The drawing was finalized using Adobe Illustrator CS6 (Adobe Systems, San Jose, CA, USA).

To produce the sets of photographs needed to compute an RTI model we used a custom-made portable light dome (PLD), whose specific technical aspects will be provided elsewhere (in preparation; a very similar setting is described in details in Kinsman, 2016). Briefly, the diameter of the PLD is $30 \mathrm{~cm}$, it is equipped with 68 white light sources (LEDs), and lighting and camera shooting are coordinated and automated. Here we generated sets of 68 photographs but used 58, the 10 highest LEDs being obstructed by the macro lens. Photographs were taken using a Canon EOS 5D Mark III digital camera (Canon, Tokyo, Japan) coupled to a Canon MPE $65 \mathrm{~mm}$ macro lens (without polarizing filters). Two sets were produced, one for an overview of the specimen and another for details of the left hind wing. Two metallic reflecting hemispheres of $1.0 \mathrm{~mm}$ in diameter (necessary to infer the position of the light source during the computing process; extracted from a ball pen and ground to obtain hemispheres) were placed next to the fossil specimen. The resulting photographs were first optimized and processed using Adobe Photoshop CS6 (Adobe Systems, San Jose, CA, USA), including auto-tone correction, edge sharpening, and the addition of a scale. The size of processed photographs ranges from ca. 13 to $18 \mathrm{MB}$. Photographs of a set were then compiled into an RTI file using the RTIbuilder software v. 2.0.2 (freely available under GNU license; using the HSH fitter). For each set, four computations were carried out: a pair for each hemisphere, and a pair for the second and third fitting orders. The latter order proved to produce slightly sharper data and was then selected. A complete RTI computation took about an hour with a computer equipped with a $3.3 \mathrm{GHz}$ processor and $8 \mathrm{~GB}$ of RAM. We provide an online Dryad dataset, cited below as "Béthoux et al. (2016)", in which the RTI files along with viewer software and instructions for use are available. Photographs reproduced herein were extracted from the RTI files (and are bookmarked in the corresponding files).

We follow the serial insect wing venation ground pattern (Lameere, 1922, 1923). The corresponding wing venation nomenclature is repeated for convenience: ScP, posterior Subcosta; RA, anterior Radius; RP, posterior Radius; M, Media; MA, anterior Media; MP, posterior Media; Cu, Cubitus; $\mathrm{CuA}$, anterior Cubitus; CuP, posterior Cubitus; $\mathrm{AA}$, anterior Analis; AA1, first branch of AA; AA2, branches of AA posterior to AA1; and AP, posterior Analis. Areas anterior and posterior to the anal fold (see below; located between AA1 and AA2) will be conventionally referred to as "remigium" and "vannus", respectively. In figures, RFW, LFW, RHW, and LHW refer to the left forewing, right forewing, right hind wing, and left hind wing, respectively. We emphasize here that it is not the aim of this contribution to address topographic homology conjectures (THCs) of the hind wing venation in Protelytroptera (see Haas and Kukalová-Peck, 2001, for alternative THCs).

The hind wing folding mechanism was investigated using a reconstruction printed on paper (Fig. 3 and Béthoux et al., 2016) and then used as model. This experiment was primarily based on data from Haas (2003) on hind wing folding in the extant Forficula auricularia Linnaeus, 1758 on the one hand (below indicated as "s1" - standing for "source 1") and on our observations of the fossil material on the other (Figs. 1, 2; "s2"). The subsequent prerequisites were assumed: (1) there is a main folding line running between AA1 and the main stem of AA2, and from which diverge radiating folds ("1st transverse fold" according to Haas, 2003; such a fold is present in Plecoptera, Mantodea, and Blattodea, at the very least, personal observation (Olivier Béthoux); in the corresponding groups it corresponds to the "anal fold" in Haas and Kukalová-Peck, 2001; herein "anal fold", in green) (s1); (2) there is a folding line crossing vein broadenings located on AA2 radiating branches ("ring fold" according to 

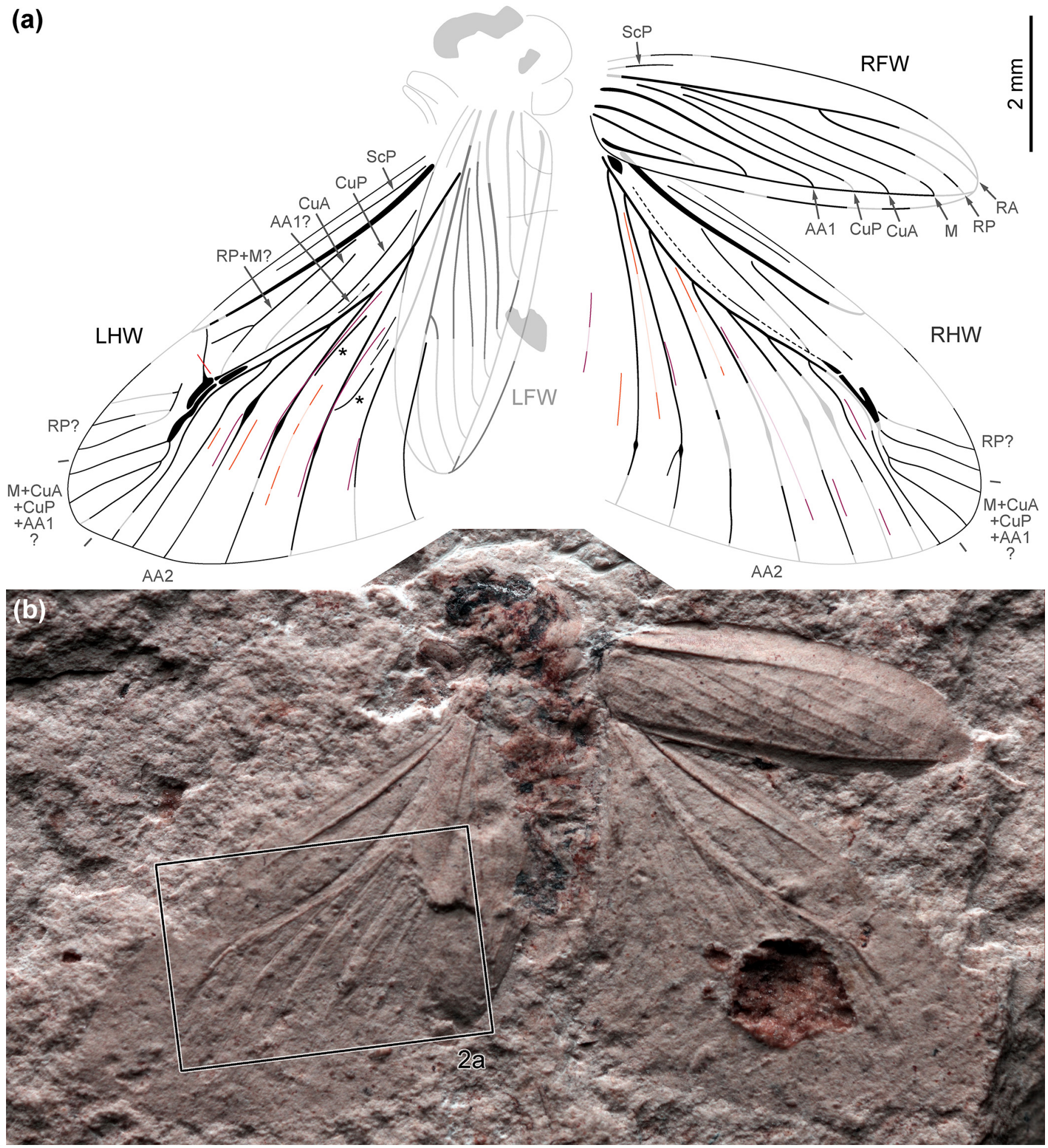

Figure 1. Protelytron permianum Tillyard, 1931, holotype (YPM IP 001019b), habitus. Interpretative drawing (a) and photograph (b side, extracted from the RTI file available from Béthoux et al., 2016) (b). See text for abbreviations and colour coding.

Haas et al., 2000; "2nd transverse fold" according to Haas, 2003; herein "ring fold", in red) (s1); (3) pairs of radiating concave and convex folds occur in areas between AA2 radiating branches ("radiating folds" according to Haas, 2003; herein "radiating folds"; convex folds in orange, concave fold in purple) (s1 and s2); and (4) there is a developed basal area, provided with veins and, possibly, radiating folds, foldable below the main part of the vannus (s2). Based on the last pre- 

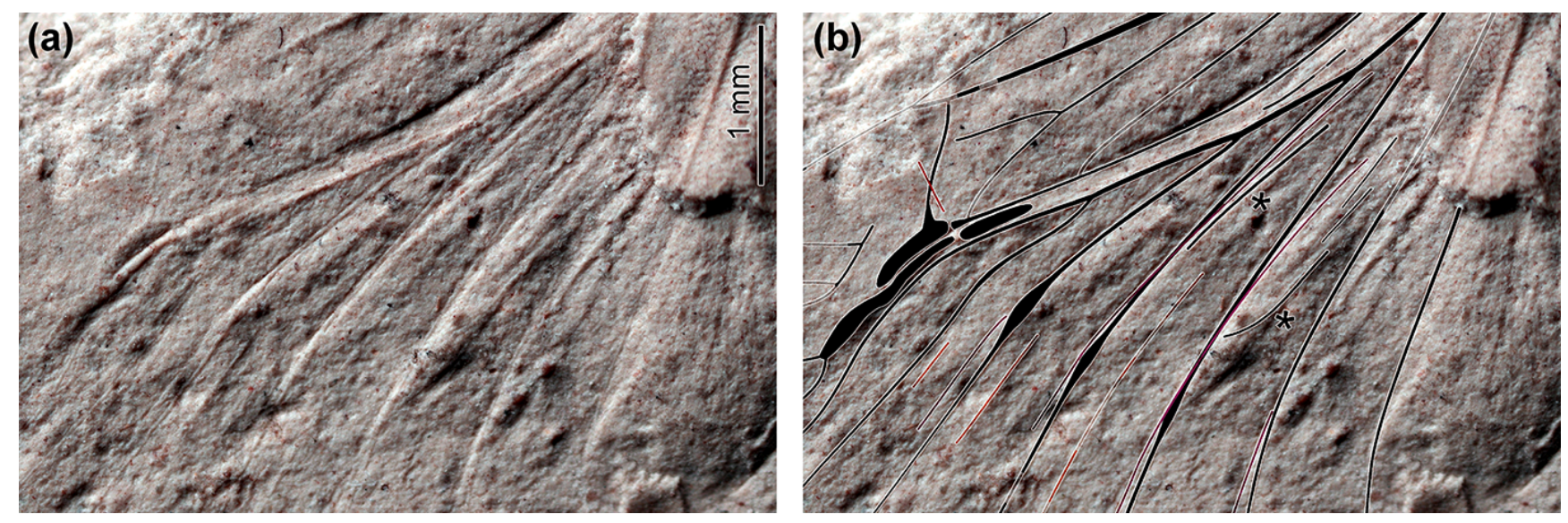

Figure 2. Protelytron permianum Tillyard, 1931, holotype (YPM IP 001019b), detail of the left hind wing as located in Fig. 1b. Photograph (extracted from the RTI file available from Béthoux et al., 2016) (a) and the same but with interpretative drawing (reproduced from Fig. 1a). See text for abbreviations and colour coding.

requisite, we assumed that the "hinge" of this area is a convex fold (herein " "jugal' fold", in blue - the term "jugal" would assume that veins posterior to it would belong to the Juga, which is not demonstrated, hence why we prefer to keep "jugal" between inverted commas). We also assumed that the fossil's hind wings were not fully unfolded because concave radiating folds seem to cross AA2 branches at some point of their course. Our reconstruction took this aspect into consideration.

Successive paper models of a right hind wing were designed. Both sides of model wings were printed on the face of a paper sheet, which was then folded and glued before being cut around the wing outlines. Folds were imprinted using a needle and a ruler (concave and convex folds were imprinted on ventral and dorsal sides, respectively). Folding was then attempted. Successive experimentations allowed us to improve the model based on mismatches between "traced" folds and folds actually resulting from the attempt. The most successful model is reproduced in Fig. 3.

\section{Results}

\subsection{Outcome of RTI process}

The reader is encouraged to download the two the RTI files which are part of a freely accessible data package (Béthoux et al., 2016). The files can be viewed and manipulated using the freely accessible RTIViewer software. Obviously, the RTI process will not generate data beyond what can be observed under a microscope with sufficient scrutiny and suitable light orientation. However, the process greatly facilitates the production of photographs requiring a very specific light orientation, as well as data sharing. Thus, the approach is particularly suited for the case presented herein. Firstly the fossilized individual has wings distributed at very different angles, rendering the production of a single, fully demonstrative photograph impossible (a compromise is reproduced in Fig. 1b). Moreover, key elements, such as vein broadenings, portions of radiating folds, and "supernumerary veins" herein interpreted as part of a basal vannal area, can be observed only under a very particular light orientation. The RTI data allowed us to extract the most appropriate light orientation to document the specimen (Figs. 1b, 2). It must be emphasized that, despite the very slight elevation of the membrane folds, the technique allowed us to obtain suitable photographs of them. This implies that the technique will be suitable for most fossil insects preserved as imprints, with the exception of the most flattened ones. Last but not least, our interpretation is open to discussion thanks to the dissemination of the interactive RTI file.

Various computer-assisted techniques have been implemented in the last decade to document the 3-D structure of objects in the form of interactive virtual objects whose lighting can be modified at will. Specimens preserving unaltered 3-D structure have been successfully investigated using serial grinding (Sutton et al., 2001; Briggs et al., 2008) and X-ray imaging techniques (Tafforeau et al., 2006). However, these approaches cannot be easily generalized to insect imprint fossils, as the former is destructive and the latter costly. Photogrammetry, which is better suited for fully exposed items preserving full 3-D structure, can be used to produce 3-D meshes, and hence interactive models (see a review in Falkingham, 2012). However, photogrammetry definitely is more computation-intensive than RTI is. This is explained by the fact that RTI does require the production of a 3-D mesh to allow interactive lighting but instead an interactive photograph directly.

Surface laser scanning (SLS) proved a workable option for such sub-plane items (Béthoux et al., 2004). However, the narrow area of application makes the acquisition of this kind 
(a)

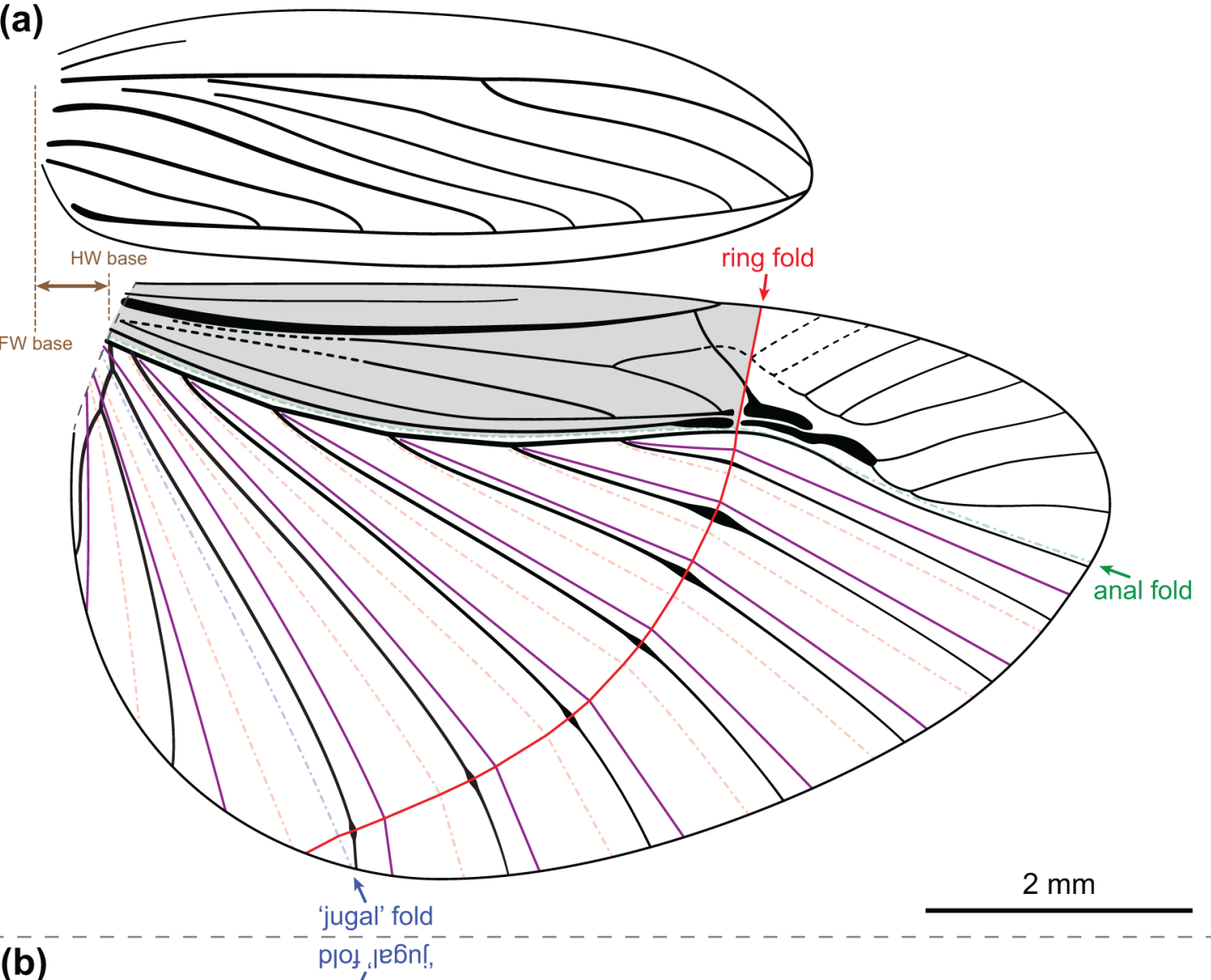

(b)

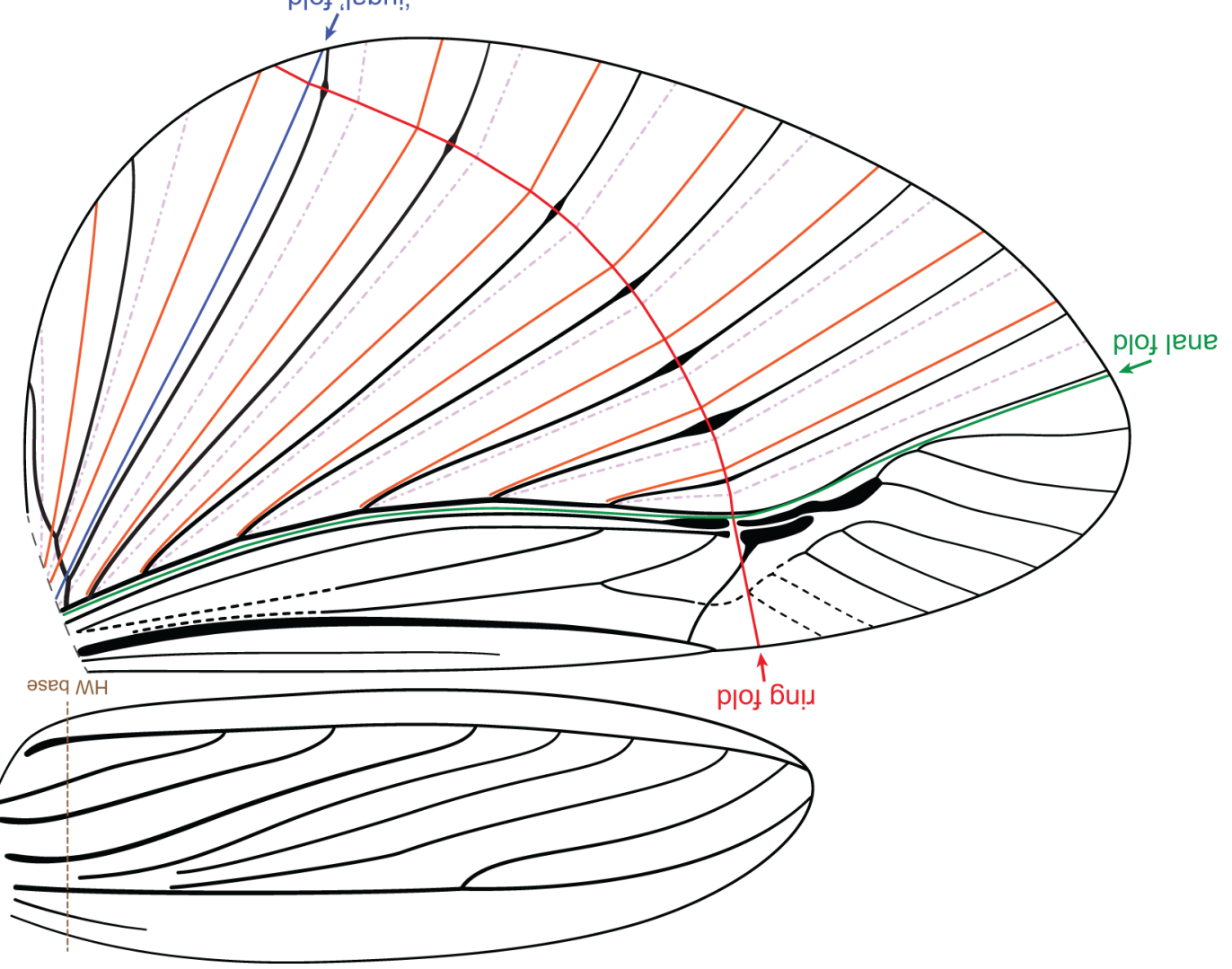


Figure 3. Template for assembly of operative models of right fore- and hind wing reconstructions of Protelytron permianum Tillyard, 1931. Dorsal (a) and ventral (b) views. See text for abbreviations and colour coding, and Béthoux et al. (2016) for a video tutorial. Assembly instructions: print the whole figure and fold along the grey dashed line; glue inner sides of paper sheet together; cut out wings along their outlines; in the hind wing, imprint the folds with a needle and a ruler; imprint concave folds (purple) on the dorsal side; imprint convex folds (green, orange, and blue) on ventral side; and imprint red fold weakly on both sides. To assist colour-blind readers, folds should be imprinted where represented by a full-colour full line (as opposed to a pale-colour dash-dotted line).

of scanner non-optimal from an institutional perspective because of its cost (and see Falkingham, 2012). Moreover, compared to our RTI setting, a surface laser scanner is not as easily transportable. The 3-D surface structure of a fossil mayfly wing could also be documented from photograph stacks (PS; Béthoux, 2015: Fig. 4). However, the tested equipment (a Keyence VHX 2000, Osaka, Japan), which is transportable, comes at a price similar to that of a surface laser scanner and uses proprietary file types, impeding data sharing. Depending on the selected camera body, our RTI setting is 8 to 14 times cheaper than such a device, can handle larger specimens, and can produce files readable with freely accessible software. In summary, cost and operability render RTI best suited for insect imprint fossils. It must be acknowledged, however, that RTI has two important disadvantages compared to SLS and PS: first, it does not provide quantitative data along the $z$ axis; second, data processing requires human input at several steps (note that data acquisition is automated).

\subsection{Specimen observation and interpretation}

We were able confirm the occurrence of vein broadenings located along AA2 branches and forming an arc in the specimen YPM IP 001019 (Fig. 2; based on photographs, broadenings also occur on the conspecific specimen MCZ 3366 in places, the specimen is erroneously referred to as " $\mathrm{MCZ}$ 3266" by Carpenter, 1933). Portions of convex and concave folds, apparently originating near the main stem of AA2, were also observed (orange and purple lines, respectively, in Figs. 1a, 2b). A number of vein-like structures, overlooked by Tillyard (1931), overlapping the main vannal area, were also observed (* in Figs. 1a, 2b). The orientation of these supernumerary elements is inconsistent with that of the wellexposed AA2 veins visible on the main vannal area. We therefore inferred the occurrence of a foldable posterior-most part of the vannus, bordered anteriorly by a main fold (herein the "jugal" fold, in blue in Fig. 3) and provided with veins. Whether this area is filled with veins pertaining to AA2 or AP cannot be determined.

\subsection{Hind wing folding mechanism}

As mentioned above, Carpenter (1933) found himself unsatisfied with the lack of knowledge on the hind wing folding mechanism in $P$. permianum. Our experimental procedure allowed us to obtain a model that is both realistic and operative. The reader is invited to print the image in Fig. 3 (also available in Béthoux et al., 2016), ideally on A3 paper, and to proceed as detailed in the corresponding figure caption (and see a video tutorial in Béthoux et al., 2016). Once the anal fold (green in Fig. 3) and radiating convex and concave folds (orange and purple, respectively) are operated, angles formed by radiating folds when reaching the ring fold (red) automatically induce the ventral bending of the area distal to the ring fold. Conversely, a full deployment of the hind wing can be achieved by manipulating its base only, implying that this operation was most probably an automated process. In other words, the use of cerci in the deployment process, as in extant Dermaptera (Haas et al., 2000), was probably not required.

The total surface of the folded hind wing is represented in light grey in Fig. 3. As a gauge of the validity of our reconstruction, this surface fits under the forewing, with the outcome that the comparatively fragile hind wing is protected under the strongly sclerotized forewing (as can be expected from a stem-dermapteran). We noted that the operation of radiating folds in the area basal to the "jugal" fold is optional to obtain this hind-wing-under-forewing fit.

\section{Conclusions}

The RTI process is particularly well suited for documenting fossil insects preserved as imprints. The resulting interactive photograph allows a user to reveal the most subtle relief information, such as subtle membrane folds. The multiple views that would be necessary to exhaustively document wings disposed at contrasting angles can be obtained and extracted. Indeed, such data can substitute, or even supplant, actual specimen manipulation. This approach has the potential to render mailing of specimens (hazardous) and visits to institutions (costly) both avoidable, at a comparatively low cost in terms of equipment and file size. Moreover, the imaging equipment can be easily transported. Finally, it could cast a new light on debated interpretations. In summary, the RTI process has a vast potential with fossil insects preserved as imprints and, possibly, with any fossil preserved on lamina, such as other arthropods, vertebrates, and plants.

With the aid of this process we have been able to ascertain that $P$. permianum is a genuine stem-dermapteran owing to the occurrence of vein broadenings located along a ring fold, as well as to the way that fold operates in conjunction with radiating folds. The approach adopted herein could be applied to other Permian stem-dermapterans such as Uralelytron martynovi Rohdendorf, 1939, for which a "triple hind 
wing folding" was proposed (Shcherbakov, 2002). The taxonomic status of the "Protelytroptera" could then be better appreciated.

Acknowledgements. We are grateful to V. Blagoderov, R. G. Beutel and J. T. Haug, and the editorial board of the journal for constructive comments; to V. Rouchon (CRCC, Paris) for introducing the RTI process to the senior author; to Susan Butts (YPM, New Haven) for allowing the loan of the specimen YPM IP 001019 and the preparation of the block containing it; and to Ricardo Perez-de la Fuente (MCZ, Harvard) for providing photographs of specimen MCZ 3366.

Edited by: D. Korn

Reviewed by: J. Haug, R. Beutel, and V. Blagoderov

\section{References}

Béthoux, O.: The Late Carboniferous Triplosoba pulchella is not a fly in the ointment but a stem-mayfly, Syst. Ent., 40, 342-356, 2015.

Béthoux, O., Mc Bride, J., and Maul, C.: Surface laser scanning on fossil insects, Palaeontology, 47, 12-19, 2004.

Béthoux, O., Llamosi, A., and Toussaint, S.: Data from: Reinvestigation of Protelytron permianum (Insecta; Early Permian; USA) as an example for applying Reflectance Transformation Imaging to insect imprint fossils, Dryad Digital Repository, doi:10.5061/dryad.94pv1, 2016.

Briggs, D. E. G., Siveter, D. J., Siveter, D. J., and Sutton, M.: Virtual fossils from 425 million-year-old volcanic ash, Am. Sc., 96, 474481, 2008.

Carpenter, F. M.: The Lower Permian Insects of Kansas. Part 6. Delopteridae, Protelytroptera, Plecoptera and a new collection of Protodonata, Odonata, Megasecoptera, Homoptera, and Psocoptera, Proc. Am. Acad. Arts Sc., 68, 411-503, doi:10.1155/1930/79267, 1933.

Earl, G., Martinez, K., and Malzbender, T.: Archaeological applications of polynomial texture mapping: analysis, conservation and representation, J. Archaeol. Sci., 37, 2040-2050, 2010.

Falkingham, P. L.: Acquisition of high resolution three-dimensional models using free, open-source, photogrammetric software, Palaeontol. Electr., 15, 1-15, 2012.

Grimaldi, D. and Engel, M. S.: Evolution of the Insects, Cambridge University Press, New York, 2005.

Haas, F.: The evolution of wing folding and flight in the Dermaptera (Insecta), Acta Zool. Crac., 46 (suppl.-Fossil Insects), 67-72, 2003.

Haas, F. and Kukalová-Peck, J.: Dermaptera hindwing structure and folding: New evidence for familial, ordinal and superordinal relationships within Neoptera (Insecta), Eur. J. Entomol., 98, 445509, doi:10.14411/eje.2001.065, 2001.

Haas, F., Gorb, S., and Wootton, R. J.: Elastic joints in dermapteran hind wings: materials and wing folding, Arth. Struct. Dev., 29, 137-146, doi:10.1016/S1467-8039(00)00025-6, 2000.
Hammer, Ø., Bengston, S., Malzbender, T., and Gleb, D.: Imaging fossils using reflectance transformation and interactive manipulation of virtual light sources, Pal. Electr., 5, 9 pp., 639KB; http: //palaeo-electronica.org/2002_1/fossils/issue1_02.htm, 2002.

Haug, J. T. and Haug, C.: Eoprosopon klugi (Brachyura) - the oldest unequivocal and most "primitive" crab reconsidered, Palaeodiversity, 7, 149-158, 2014.

Hennig, W.: Insect Phylogeny, Wiley \& Sons, New York, 1981.

Kinsman, T.: An easy to build reflectance transformation imaging (RTI) system, J. Biocom., 40, 10-14, 2016.

Lameere, A.: Sur la nervation alaire des Insectes, Bull. Cl. Sc. Acad. Roy. Belg., 8, 138-149, 1922.

Lameere, A.: On the wing-venation of insects, Psyche, 30, 123-132, doi:10.1155/1923/16920, 1923.

Laurentiaux, D.: Classe des Insectes (Insecta Linné, 1758), in: Traité de Paléontologie, edited by: Piveteau, J., Masson et Cie, Paris, 1953.

Linnaeus, C.: Systema naturæ per regna tria naturæ, secundum classes, ordines, genera, species, cum characteribus, differentiis, synonymis, locis, Stockholm, 1758.

Nel, A., Albouy, V., Caussanel, C., and Jamet, C.: Réflexion paléoentomologique sur la systématique des Dermaptères. Quatre nouveaux forficules fossiles de l'Oligocène de Provence (France) (Dermaptera), Bull. Soc. Entomol. Fr., 99, 253-266, 1994.

Rohdendorf, B. B.: Predstavietil otryada Protelytroptera iz uralskoï Permi [A representative of the order Protelytroptera from the Permian of the Urals], Dok. Akad. Nauk SSSR, 23, 506-508, 1939.

Rohdendorf, B. B.: Podtip Mandibulata Zhvalonosnye chlenistonogie [Subphylum Mandibulata or Prototracheata], in: Osnovy Paleontologii [Fundamentals of Palaeontology], edited by: Rohdendorf, B. B., Izdatel'stvo Akademii Nauk SSSR, Moscow, 1962.

Rohdendorf, B. B. (Ed.): Fundamentals of Paleontology, Volume 9: Arthropoda: Tracheata and Chelicerata, Smithsonian Institution Libraries, Washington, 1991.

Shcherbakov, D. E.: Order Forciculida Latreille, 1810. The earwigs and the protelytropterans (=Dermaptera DeGeer, 1773 + Protelytroptera Tillyard, 1931), in: History of Insects, edited by: Rasnitsyn, A. P. and Quicke, D. L. J., Kluwer Academic Publishers, Dordrecht, 2002.

Sutton, M. D., Briggs, D. E. G., Siveter, D. J., and Siveter, D. J.: Methodologies for the visualization and reconstruction of threedimensional fossils from the Silurian Herefordshire Lagerstätte, Palaeontol. Electr., 4, 1-17, 2001.

Tafforeau, P., Boistel, R., Boller, E., Bravin, A., Brunet, M., Chaimanee, Y., Cloetens, P., Feist, M., Hoszowska, J., Jaeger, J.-J., Kay, R. F., Lazzari, V., Marivaux, L., Nel, A., Nemoz, C., Thibault, X., Vignaud, P., and Zabler, S.: Applications of X-ray synchrotron microtomography for non-destructive 3D studies of paleontological specimens, Appl. Phys. A, 83, 195-202, 2006.

Tillyard, R. J.: Kansas Permian insects. Part 13. The new order Protelytroptera, with a discussion of its relationships, Am. J. Sc., 21, 232-266, doi:10.2475/ajs.s5-21.123.232, 1931.

Zhao, J., Zhao, Y., Shih, C., Ren, D., and Wang, Y.: Transitional fossil earwigs - a missing link in Dermaptera evolution, BMC Evol. Biol., 344, 2010, doi:10.1186/1471-2148-10-344, 2010. 